\title{
Some notes on approaches to regulatory capital assessment for insurance firms
}

\section{Turnbull*}

\begin{abstract}
The intellectual climate around financial solvency regulation has changed markedly since the global financial crisis, especially with regard to the usefulness of market prices, the desirability of principle-based solvency assessment, the feasibility of a probabilistic approach to produce accurate capital estimates, and indeed whether solvency assessment should be risk-sensitive at all. This short paper provides some reflective notes on approaches to solvency capital assessment for insurance firms in this context.
\end{abstract}

\section{Keywords}

Solvency Capital Assessment; Value-At-Risk; Principle-Based Reserving

\section{Introduction}

Following its extraordinary gestation period, the introduction of Solvency II across the European Union at the start of 2016 might have reasonably been expected to mark the start of a period of relative tranquillity in the formulation of regulatory capital assessment for insurance firms. Experience since then, however, suggests such an expectation may be ill-founded: indeed, it seems quite likely that the regulatory solvency regime for insurance firms in the EU, and in the United Kingdom in particular, is likely to continue to significantly evolve in the coming years.

There are a few reasons for anticipating significant ongoing change: the economic environment continues to be exceptionally challenging for long-term liability books in northern Continental Europe in particular, and the resulting tensions between policyholder security, macro-stability and political expediency may continue to drive adjustments to the Solvency II system in ways that are difficult to predict; Solvency II represents a complex and fundamental change in approach to solvency regulation for many EU countries and so some refinement in the light of early experience is natural; and, for the United Kingdom in particular, its impending exit from the EU in the coming years potentially raises the entirely unexpected prospect of the approach to regulatory solvency assessment of UK financial institutions being re-written on a blank piece of paper.

Unlike most of the global financial regulation that has been developed and adopted since the global financial crisis of $2007 / 2008$, Solvency II was not a reaction to that crisis. Indeed, its conception pre-dated the crisis by a decade. This is interesting because the intellectual climate around 
financial regulation has been profoundly impacted by the global financial crisis and the political and regulatory reaction to it. Thus, the zeitgeist of 2020 may be quite different to 2000 with regard to how insurance industry leaders, academics and regulators articulate an ideal regulatory solvency capital assessment framework for insurance firms and other financial institutions.

This short paper provides some reflective notes on approaches to solvency capital assessment for insurance firms given this context. These notes are primarily driven by considerations of solvency capital approaches for financial market risk, but most of the points have wider applicability. The structure of the remainder of the note is as follows:

- Section 2 provides an overview of the technical arguments for and against different quantitative approaches to risk-based capital assessment. This discussion considers questions such as: what are the relative merits of principle-based and rules-based solvency systems? What are the different measurement challenges entailed by different quantitative definitions of the capital requirement?

- Section 3 notes and reflects on some contemporary commentary from industry thought-leaders on approaches to solvency capital assessment in today's environment. This will aim to demonstrate how the intellectual climate around financial solvency regulation has changed since the global financial crisis, especially with regard to the usefulness of market prices, the desirability of principle-based solvency assessment, the feasibility of a probabilistic approach to produce accurate capital estimates and indeed whether solvency assessment should be risk-sensitive at all.

- Finally, section 4 provides some historical perspective by considering an approach to solvency capital assessment that has historically been implemented in the UK life industry. This focusses on different forms of governance framework for principle-based capital assessment.

\section{On different quantitative frameworks for risk-sensitive capital assessment}

The quantitative methodological frameworks used around the world today in the assessment of the regulatory solvency capital requirements of financial institutions are usually explicitly probabilistic and risk-sensitive. Indeed, the desirability of a risk-sensitive approach to insurance solvency capital assessment is captured in the International Association of Insurance Supervisors' (IAIS) Insurance Core Principles, which states that approaches to solvency assessment "should be designed to deliver capital requirements which reasonably reflect the overall risk to which insurers are exposed" (2015, page 211 (ICP 17.6.8)).

The technical design of a probabilistic measure of the capital requirement can vary in many ways, but there are a couple of critical factors that determine the key characteristics of the adopted approach:

- Market values versus cashflow funding: Is the definition of the capital requirement based on a measure of the short-term ${ }^{1}$ (e.g. 1 year) potential for a deterioration in the market value-based balance sheet of the institution's assets and liabilities; or is the measure based on the long-term (e.g. ultimate run-off horizon of the liability book) potential for a deterioration in the net cashflows generated by the assets and liabilities?

1 The 1-year horizon is used in Solvency II, but other horizons could also be chosen. The conceptual rationale for the choice of horizon under the market value-based capital approach is based on the length of time it would take to arrange the transfer of the risks on the balance sheet to a willing third party. Banks typically use much shorter horizons (days) in the capital assessment of their trading book, on the assumption that their (liquid) asset risks can be quickly transferred to market counter-parties. 
- Principle-based versus rules-based: Should the capital be assessed using a formulaic methodology laid down by the regulator and applied uniformly by all firms; or should firms have the freedom to develop risk measurement methodologies that are intended to best reflect the specific profile of the risks that their balance sheet is exposed to?

Books can be written on the many arguments for and against each of these design choices for risksensitive capital assessment. Below, a brief summary of some of the key arguments that tend to arise in this debate are provided.

\subsection{Arguments for and against the market value-based solvency approach versus the cashflow funding approach}

Arguments for a market value-based solvency approach as opposed to a cashflow funding approach:

- The purpose of regulatory capital is to provide policyholder security - that is to ensure there is a very high probability that the insurer will be able to make good on the specific (contingent) assurances it is contracted to deliver to policyholders. These assurances are recognised as liabilities on the firm's balance sheet. The sufficiency of existing assets to fund the full cost of transferring these liabilities to a third party provides a strong, objective and relevant measure of policyholder security. A market value-based approach to asset and liability valuation provides the natural basis for this assessment of cost. ${ }^{2}$

- The cashflow funding approach relies on very long-term estimates of the behaviour of economic variables, mortality experience and policyholder behaviour in atypical, stressed circumstances. It is extremely difficult to develop robust methods for calibrating and validating such assumptions, and the results of the cashflow funding approach are highly sensitive to these assumptions. ${ }^{3}$

Arguments for a cashflow funding approach rather than a market value-based approach:

- The market prices of financial assets tend to exhibit short-term behaviour that is difficult to reconcile with rational changes in expectations for long-term cashflows as the primary driver for their changes. This empirical behaviour has long been well-established in financial economics research (see, e.g. Shiller, 1981; Fama and French, 1988; Roll, 1988). This work implies that asset risk and liquidity premia, asset price volatility and Sharpe ratios all vary significantly over time ${ }^{4}$ (though economic theories that explain this empirical behaviour are not so well-established). A short-term market value approach to capital assessment will therefore produce changes in capital assessments over time which will appear excessive relative to those implied by a cashflow funding adequacy approach. ${ }^{5}$ Moreover, this will induce pro-cyclical behaviour, compelling

${ }^{2}$ It may be argued that an allowance for the transaction costs incurred in switching the current asset portfolio into the liability-matching portfolio under the stress event should be incorporated into the assessed impact of the stress on the asset market value.

${ }^{3}$ A counter-argument is to point out that it is just as difficult to estimate the $99.5^{\text {th }}$ percentile of a 1-year tail as it is to estimate, say, the $95^{\text {th }}$ percentile of a 10 -year tail. Whilst it is certainly the case that estimation of the more extreme percentile of a given distribution will entail greater estimation uncertainty, it should be borne in mind that 10-year distributions have significantly fewer relevant historical data points to use in the estimation, and that the estimation of any percentile of 10 -year is sensitive to assumptions about the (time-varying) path behaviour of asset prices and their risk premia.

4 See Part IV, Cochrane (2001) for a fuller discussion.

5 Perhaps a difficulty with this argument is that it is difficult to know, at any point in time, whether a significant fall in (risky) asset prices reflects a large change in the asset risk premium or fall in its expected future cashflows. How much credit should a solvency capital assessment be able to claim for the subjective assumption that market prices have reached a point where the assets are, in some fundamental sense, cheap? 
insurers to sell "low-price" assets (i.e. at the times they offer large asset risk premia), further contributing to excessive short-term market volatility. This has potentially significant macroprudential implications for financial stability and is damaging to the interests of insurance firms' shareholders and policyholders.

- Insurers have (some) uniquely illiquid long-term liabilities. For these liabilities, the near-term ability of the insurance firm to fund the cost of transfer of the liabilities to a third party is not relevant. The only measure of ultimate interest is the degree of confidence that can reasonably be attached to the insurer's ability to meet the liability obligations as and when they ultimately fall due. This is precisely what the cashflow funding approach attempts to measure.

\subsection{Arguments for and against principle-based versus rules-based approaches}

Arguments for a principle-based approach rather than a rules-based approach:

- Under a rules-based system of solvency capital assessment, institutions will be incentivised to exploit the rule book's limitations: the risk measurement rules may hence create perverse risk management strategy incentives. If the rule book varies by type of institution or by geography, the opportunity and incentive to participate in regulatory arbitrage will arise. These incentives will compel the regulatory authorities to develop ever more complex sets of rules that aim to address the most recent act of subversion - ad infinitum. Under a principle-based system, the risk measurement is adapted to best reflect whatever risk management strategy is put in place, and firms arguably have more incentive to focus their energies on genuinely managing risk.

Arguments for a rules-based approach rather than a principle-based approach:

- Given the freedom of a principle-based framework, financial institutions will be incentivised to develop risk measurement methods that systematically under-estimate the true risk exposures on the firm's balance sheet. Large firms will always be able to afford more intellectual and technological firepower than regulators, and will be able to stay a step ahead. There is some evidence of behaviour in banks prior to the global financial crisis that provides support to this argument - for example, the documented tendency of "model drift" whereby internal models of risk are evolved over time to reduce capital in the absence of any corresponding reduction in risk. This remains a concern of regulators where principle-based methods are permitted (see, e.g. Prudential Regulation Authority, 2016).

- A rules-based approach should be simpler, more transparent and cheaper to implement (for both financial institutions and their regulators) than a principle-based system.

\section{Contemporary Commentary on Solvency Regulation of Insurance Firms and Other Financial Institutions}

The above arguments appear quite finely balanced, and the consensus view on them has historically waxed and waned over time, influenced by prevailing economic conditions and the contemporaneous performance and behaviour of financial institutions.

Thought-leadership in global financial regulation in the early 2000s was generally in support of using market value-based and principle-based approaches to regulatory solvency capital assessment. In global banking, the New Basel Capital Accord readily embraced these properties (at least for bank's trading books, if not loan books). In UK life assurance, the struggles that life assurers experienced in 
measuring the market risk exposures of Guaranteed Annuity Options (GAOs) in the late 1990s provided a new impetus for the speedy development of an improved regulatory solvency framework for UK insurance firms. In their British Actuarial Journal paper of 2004, Sheldon and Smith noted:

"The introduction of the realistic balance sheet is, in part, a response to the difficulties that un-hedged guarantees have caused the life industry in recent years. Reliance on long-term solvency tests runs the risk that we overlook more imminent problems, compounded by the use of overoptimistic assumptions and models used to determine capital needs. While there has been some criticism of the transfer of banking techniques to life assurance, the rate of deterioration in life offices' finances over the last three years demands a greater focus on the short term" (2004, page 547).

The experience of the global financial crisis and its aftermath has altered the early 2000s' near-global consensus for the use of principle-based, market value-based regulatory solvency capital assessment approaches in financial institutions. Below are some examples of relevant contemporary commentary from notable thought-leaders that employ some of the arguments identified in section 2 against the use of principle-based and market value-based regulatory capital assessment approaches (and in one case, even against the use of any form of risk-sensitive capital measure).

Tom Wilson, the Group Chief Risk Officer of Allianz, and a notable long-standing proponent of market value-based reform of the financial reporting and risk management of insurance groups, argued in his recent book, Value and Capital Management, that "market-consistent approaches make a horrible basis for solvency rules" because "short-term fluctuations in market risk aversion and the associated 'flight to quality' can cause major dislocations which do not reflect the underlying variability or cashflow solvency of the business" (2015, pages 123-124).

Mr Wilson's position is interesting as he maintains that movements in market value-based asset and liability valuations remain the preferable way to assess and report shareholder profit and to manage shareholders' financial market risk. He recognises that the full use of market prices in shareholder value management and reporting together with the rejection of the relevance of market prices for use in regulatory capital assessment represents a "paradox" that he explains is due to the realisation that "shareholder value and policyholder security are not as perfectly aligned as originally thought when Solvency II was being developed" (Wilson, 2015, page 123). Mr Wilson uses the example of a book of fixed annuities written in Germany and backed by Italian sovereign bonds. Writing such business in the years prior to the global financial crisis would have led to substantial shareholder value destruction in the years following the crisis, as represented by the fall in the value of the assets that resulted from a substantial increase in Italian bond spreads. But, he argues, this might not necessarily have had any impact on policyholder security, as the increase in bond spreads might be entirely due to an increase in market risk aversion rather than security of the cashflows.

Is this argument strong enough to be used in assessing policyholder security? Should not policyholder security be more prudently treated than shareholder value than vice versa? Is it reasonable, when the market value of assets is less than the cost of a perfect liability-matching portfolio, to, on the one hand, tell shareholders that the value of this business is negative and that management would gladly pay someone to take it off their hands, but on the other, simultaneously tell policyholders and regulators that they are extremely confident that the existing assets will be sufficient to meet the promised policy pay-outs?

This position would seem to rely on two premisses: it is possible to know when current market prices are "abnormally low" (not with the benefit of hindsight), and to have extremely high confidence in 
them reverting to the "normal" level in due course; and when these obvious short-term aberrations in market prices occur, an insurer's policyholders should not worry about how the insurer manages market value risk, but the insurer's shareholders should. Both these premisses seem stretching. The first would seem to suggest the insurance executive is in the wrong job (surely these skills could be more profitably applied to a career as a hedge fund manager). With regard to the second, unlike shareholders, policyholders in non-profit insurance contracts do not participate in market upside risk and so, unlike shareholders, they do not have an obvious incentive to back management's subjective beliefs in financial market valuations to a greater degree than shareholders.

Lord Turnbull, the former Cabinet Secretary, in his submission of evidence to the Treasury Select Committee Inquiry on the UK's Future Economic Relationship with the European Union stated "I personally think Solvency II ... is an absolutely dreadful piece of legislation, because it treats insurance companies as though they were banks, as though they had to mark to market every day, because their liabilities could disappear every day, as they can with banks". ${ }^{6}$

Lord Turnbull's point is essentially the same as Mr Wilson's: the assessment of the security of longterm illiquid liabilities should not be overly concerned with short-term asset market price volatility. Given Lord Turnbull's particular reference to "liabilities (that) could disappear every day", it is worth noting that Solvency II does have a feature, the "Matching Adjustment", which permits the capital assessment of suitably illiquid liabilities to ignore much short-term asset volatility. ${ }^{7}$ Thus, it might be counter-argued that the "mark to market every day" feature of Solvency II is, in the main, only applied to the insurance liabilities that could indeed "disappear every day".

The IAIS (2016) is currently consulting on the development of a "Risk-Based Global Insurance Capital Standard", which all insurance firms deemed as internationally active would be required to implement. In the consultation, the proposed solvency measure is a 1-year value-at-risk measure, and so appears similar in structure to the market value-based solvency approach used in Solvency II. But the extent to which the valuations would be based on market value measures of assets and liabilities is an open topic of the consultation. The consultation does not consider whether an internal model approach to capital assessment can be used (but does not rule out the possibility of considering it in subsequent iterations of the Capital Standard). Its positions on a principle-based approach versus a rules-based approach and on a market value versus cashflow funding approach therefore seems, at most, neutral.

The past Governor of the Bank of England, Lord King, published a book recently, The End of Alchemy, in which he rejected principle-based capital methods for banks (and perhaps implicitly for other forms of financial institution), arguing that the institutions' internal risk and capital measures were unreliable and uninformative: "It is extremely difficult, if not impossible, to judge how the riskiness of different assets will change in the future" and "it is more sensible to recognise that the pretence that it is possible to calibrate risk weights is an illusion". Thus, the use of risk-based methods "can be highly mis-leading" (King, 2016, pages 138-140, 258).

6 Treasury Select Committee (2016), Lord Turnbull's response to Q21.

7 The use of the Matching Adjustment has two distinct impacts on capital: it increases capital resources by reducing the value of liabilities through the incorporation of most or all of the asset portfolio's risk premium into the liability discount rate; and it reduces the credit risk capital requirement as it assumes that a portion of any increase in the asset credit spread can be incorporated into the new liability discount rate. As an asset portfolio moves from risk-free bonds to BBB credit quality, the net capital impact tends to be insignificant: the increase in capital resources tends to broadly be of similar size to the increase in capital requirements. The counter-intuitive nature of this behaviour is noted and discussed in Rae et al. (2017), section 2.1.2. 
He argues for a vastly simplified capital assessment system based on fixed maximum leverage ratios for all banks (equivalent to a fixed minimum solvency margin for insurers), irrespective of the levels of asset risk on their balance sheet. Such a system would be neither principle-based nor even risk-sensitive.

The notion of a solvency capital system that has no risk sensitivity may strike most actuaries as alarming and perhaps even absurd (and, as noted above, is contrary to the IAIS Core Principles). However, many actuaries, and other risk-minded finance professionals, may sympathise with the philosophical idea that financial market risk is fundamentally uncertain and cannot be reliably quantified by reference to historical data or indeed to any other information. The early $20^{\text {th }}$ century American economist Frank Knight's (1921) distinction between (measurable) risk and (unmeasurable) uncertainty is a natural intellectual reference point in this context. And such scepticism has philosophical grounds that can be traced back at least as far as David Hume in 1751, when he succinctly noted:

"If there be any suspicion that the course of nature may change ... all experience becomes useless, and can give rise to no inference or conclusion" (1751).

Some of the experiences of the last decade may lend further weight to Lord King's perspective that finding approaches to reliable estimation of the probabilities attached to financial market behaviour is a futile exercise. For example, the revelation by the Goldman Sachs Chief Financial Officer in 2008 that, according to the firm's internal capital models, they had experienced several 25 -standard deviation events over the course of a couple of weeks, suggests the models were not working very well. The recent experience of large European life assurers provides another example. These firms invested significantly in financial risk modelling apparatus over the prior 10 years or so, driven both by anticipation of Solvency II and as part of the wider embrace of "Enterprise Risk Management". The biggest form of risk exposure on these firms' balance sheets was to significant falls in long-term interest rates. These rates did indeed fall. And the models in use at the time did not attach any meaningful probability to the size of the fall in long-term interest rates that occurred.

The above calls into question the usefulness of an explicitly probabilistic approach to defining a risk capital standard. But what are the non-probabilistic alternative frameworks for defining a risksensitive measure of risk capital? There are not many obvious candidates - it is difficult to foresee how to measure risk in units of something that is not founded on a probabilistic description of the future. Stresses could be specified without any probabilistic interpretation being attached to them, but under such an approach, how is the "strength" of the stress to be determined? Conceptually, one potential approach could be to specify the conditions in which the firm's capital is not intended to be sufficient to meet their liabilities (without attaching a probability to such conditions arising). For example, one such condition might be the firm's national government defaulting on its own debt. This could provide a quite intuitive and explicit explanation of what the capital does and does not do. However, it may be difficult to generalise this concept so that it can be effectively applied in the context of the many forms of (financial and non-financial) risks that can be found on insurance firms' balance sheets.

All of the above suggests that the last decade or so has seen the emergence of some strong and influential doubts about whether a market value-based, principle-based solvency capital assessment system is now recognised as the best practice model for solvency regulation of the insurance industry.

Finally, it is perhaps worth explicitly recognising that the technical methodologies of the risk capital assessment can only play a limited role in ensuring the soundness of financial institutions. Culture, 
governance, incentives and accepted norms of behaviour will ultimately be the primary determinants of the health of the financial services sector. The circumstances surrounding the global financial crisis have provided evidence of dubious incentives and unattractive cultural norms within some financial institutions. This has generated huge public criticism and calls for wider reform of the sector by leading thinkers. ${ }^{8}$ Whilst most of this criticism has been directed at banks and financial conglomerates, the erosion of public trust in financial institutions and professionals working in the financial services industry will inevitably impact on insurance groups and actuaries.

\section{A Historical Perspective}

The British actuarial profession, with its long history of assessing the adequacy of the funding of long-term liabilities in insurance firms and pension funds, can provide some long-term historical perspective on the arguments raised above.

For example, in the $18^{\text {th }}$ century, in one of the earliest documented discussions of an actuarial approach to life assurance reserving, James Dodson explicitly used consideration of the cost of transfer of the liabilities to a third party to frame his reserving logic:

"Now let us suppose that the corporation will contract with some other body, take the insuring of these off their hands by a payment of a sum in hand" (1756, chapter 3).

The field of Defined Benefit pension funds has borne witness to periods of intense actuarial debate on whether a market value-based or cashflow funding-based approach to assessing the financial health of long-term pension funds was most appropriate. In general, the mainstream view of the profession has remained firmly in the cashflow funding camp. But there has also been strong actuarial advocacy of putting an at least equal focus on the short-term sufficiency of assets to secure liabilities through the transfer of risk to a third party. For example, in 1987, the British pension actuaries McLeish and Stewart argued:

"The prime purpose of funding an occupational pension scheme must be to secure the accrued benefits, whatever they might be, in the event of the employer being unable or unwilling to continue to pay at some time in the future. To that end, the contributions would have to be sufficient both to pay the benefits as they fell due for as long as the scheme continued, and also to establish and maintain a fund which would be sufficient to secure the accrued benefits in the event of contributions ceasing and the scheme being discontinued, whenever that might occur" (1987, page 155).

From the late $19^{\text {th }}$ century to the 1970 s, actuarial reserving in UK life assurance worked under what was known as the "freedom with publicity" regime. This was essentially a principle-based reserving framework that gave the actuary considerable discretion in their choice of reserving methods, but also required the actuary to make full disclosure of the methods that he or she had applied.

In 1976, when arguing for the extension of this "freedom with publicity" system from life assurance to general insurance, Sydney Benjamin succinctly summarised its key features as follows:

"The actuary, in publishing his valuation, is required to state publicly exactly how he arrived at it, the data he used, the assumptions he made and his treatment of special points. Great effort has been expended in designing the form of his report so that he should do this in a way which will allow an independent outsider to check his results, and to see what effect a change in his basis would produce on that data" (1976).

${ }^{8}$ See, for example, Kay (2015) for a recent and excellent commentary on this topic. 
This preference for full public disclosure over prescriptive government regulation was wellestablished in the thinking of the British actuarial profession from the late $19^{\text {th }}$ century. The minutes of discussion amongst the actuarial leaders of the time at the Second International Congress of Actuaries in 1898 (particularly George King and Dr Sprague) provide some illuminating examples.

Benjamin's description captures the essence of a principle-based system, and arguably has some advantages over the Internal Model regime of Solvency II as a framework for principle-based capital assessment. In the Internal Model system, the model is not publicly disclosed and must be submitted to the national insurance regulator for prior approval. This can create a slow, technocratic process, which puts a heavy burden on the limited resources of the regulator, and arguably confuses accountability. (If the regulator approved the model, is the firm or the regulator really responsible if it turns out to be inadequate?)

The "freedom with publicity" system of full public disclosure and scrutiny is closer to a true principle-based framework, and the potential benefits of principle-based reserving are accordingly of greater prospect in such a system. Many will be rightly sceptical about whether the system that produced the GAOs crisis and the Equitable Life debacle could be a model of effective regulation. But it does offer some examples of success outside the arcane and largely defunct world of with-profit business - for example, in reserving for guarantees in unit-linked business. ${ }^{9}$ Nonetheless, a true principle-based system such as an effectively administered "freedom with publicity" regime requires a level of trust in the professional judgement and objectivity of senior staff within financial institutions that is perhaps not present in post-global financial crisis society.

\section{Closing Thoughts}

These notes only attempt to scratch the surface of this important and multi-faceted topic. Nonetheless, I hope they have done enough to demonstrate that it is clear there is likely to be much ongoing debate about how to design and implement an effective risk-sensitive solvency capital assessment framework for insurance firms, and there is much scope for the actuarial profession to make a proactive and valuable contribution to this debate.

\section{Acknowledgements}

The author would like to thank Dr David Hare, with whom the author had some stimulating discussions that provided the author with the original motivation to commit some of these thoughts to paper. The author would also like to thank Professor John Hibbert, whose feedback and challenges substantially enriched these notes. Finally, the author would like to thank the two anonymous scrutineers for their useful and insightful comments. All opinion and errors are the author's alone.

\section{References}

Benjamin, A.R. (1899). On Legislation in the United Kingdom as affecting the Life Assurance Contract, Transactions of the Second International Congress of Actuaries.

Benjamin, S. (1976). Profit and other financial concepts in insurance. Journal of the Institute of Actuaries, 103(3), 233-305.

Cochrane, J. (2001). Asset Pricing. Princeton: Princeton University Press.

\footnotetext{
9 See Turnbull (2016) for a fuller discussion.
} 
Dodson, J. (1756). First Lectures in Insurance.

Fama, E. \& French, K. (1988). Permanent and temporary components of stock prices. Journal of Political Economy, 96, 246-273.

Hume, D. (1751). An Enquiry Concerning Human Understanding.

International Association of Insurance Supervisors (IAIS) (2015). Insurance Core Principles, available at http://www.iaisweb.org/ (accessed 26 December 2017).

International Association of Insurance Supervisors (IAIS) (2016). Risk-Based Global Insurance Capital Standard Consultation Document, available at http://www.iaisweb.org/ (accessed 26 December 2017).

Kay, J. (2015). Other People's Money. London: Profile Books.

King, L. (2016). The End of Alchemy. London: Little, Brown.

Knight, F. (1921). Risk, Uncertainty and Profit. New York: Hart, Schaffner \& Marx.

McLeish, D.J.D. \& Stewart, C.M. (1987). Objectives and methods of funding defined benefit pension schemes. Journal of the Institute of Actuaries, 114(2), 155-225.

Prudential Regulation Authority (2016). Solvency II: Monitoring model drift and standard formula SCR reporting for firms with an approved internal model. Consultation Paper 22/16, available at https://www.bankofengland.co.uk/prudential-regulation/publication/2016/ solvency-2-monitoring-model-drift-and-standard-formula-scr-reporting-for-firms-with-anapproved (accessed 26 December 2017).

Rae et al. (2017), A review of Solvency II - has it met its objectives. British Actuarial Journal (forthcoming).

Roll, R. (1988). ), "R $\mathrm{R}^{2}$. Journal of Finance, 43(3), 541-566.

Sheldon, T.J. \& Smith, A.D. (2004). Market-consistent valuation of a life assurance business. British Actuarial Journal, 10(3), 543-626.

Shiller, R.J. (1981). Do stock prices move too much to be justified by subsequent changes in dividends? American Economic Review, 71(3), 421-436.

Treasury Select Committee (2016). Oral evidence: follow up to the Committee's Report on the UK's future economic relationship with the European Union, HC 483.

Turnbull, L.C. (2016). A History of British Actuarial Thought. London: Palgrave Macmillan.

Wilson, T. (2015). Value and Capital Management. London: Wiley. 